The Molecular Biology of Development

by James Bonner

Oxford University Press

A book for biologists who want to learn about those portions of molecular biology which pertain to the study of development, and for molecular biologists who want to consider some of the ways in which the insight of modern biology may be applied to developmental matters.

Dr. Bonner, professor of biology at Caltech, wrote the book during his recent tenure of the Eastman Visiting Professorship. Quantum Mechanics and
Path Integrals

by R. P. Feynman and A. R. Hibbs

McGraw-Hill $\$ 12.50$

Reviewed by Jon Mathews, associate professor of theoretical physics.

In the vigorously active and competitive world of contemporary physics, very few ideas or techniques remain for long the property of their creator. Ideas in this area are rarely patented, and inventors can usually hope only that their contribution will not be totally submerged in the avalanche of papers that follows each new idea. The path integral concept, developed originally by Feynman as a graduate student some 25 years ago, is an exception. It has been left for Feynman, now Tolman Professor of Theoretical Physics at Caltech, with the assistance of A. R. Hibbs, a former student of his now at the Jet Propulsion Laboratory, to present in this book the first systematic discussion of path integrals in quantum mechanics.

According to the dust jacket, the book is intended as a supplement for first-year graduate courses in quantum mechanics, as an introduction to path integrals for physicists already familiar with quantum mechanics, and as a source book for Feynman's contributions in this area. The validity of the second and third purposes is beyond question; the writing combines clarity, informality, and physical insight with admirable effect. However, it is a rare first-year graduate student who has acquired sufficient feeling for quantum mechanics and quantum statistics for the elegance of Feynman's reformulation to come through.

The situation is reminiscent of the introduction of the Feynman lectures to the freshmen and sophomores at Caltech. Arguments were made, before and after the changeover, that the material could not be fully comprehended by lower division undergraduates. Nevertheless, the experiment was successful. Only the passage of time can tell whether the path integral approach to quantum mechanics, which is set forth so elegantly by Feynman and Hibbs in this book, will similarly affect the teaching of quantum mechanics at the graduate level.

\section{The Machinery of Life}

by Dean E. Wooldridge, PhD'36

McGraw-Hill $\$ 7.95$

Reviewed by G. D. McCann, professor of electrical engineering and director of the Booth Computing Center.

Dean Wooldridge is a research associate in engineering at Caltech and a director of TRW, Inc. During the past few years he has become intensely interested in the examination of the life sciences from the viewpoint of a physicist. His first book, The Machinery of the Brain (McGraw-Hill, 1963), dealt with explanations of the functional properties of the brain and nervous system. This book is concerned primarily with the structure of living organisms in terms of successively more complex building blocks. Wooldridge takes a viewpoint that this structure can be understood as a logical extension of the physical laws of the inorganic atoms and molecules.

Starting with the prehistoric geophysical state of the earth, which provided the environment for the origins of the "pre-life" organisms, he develops in a relatively clear and precise manner the detailed steps that scientific research indicates were necessary for the evolution of primitive life and the higher living systems leading to man.

This is a semi-popular book, and yet it contains a remarkably thorough treatment of the amino acid-protein and the nucleonic acid structures, together with their roles in the formation and functioning of living organisms.

This description of the physically known properties of extremely complex chains of molecules supports his thesis that, as man understands life in physical terms, life loses its mystical properties. Admittedly, however, our knowledge of the living organisms is not yet sufficiently complete to explain the more comprehensive, larger, living systems or more complete animals, to the extent that we can have the conviction that the complex functions and behavior properties of man can also be explained in such physical terms.

The Uncommon Man in American Business

by Wallace J. S. Johnson, '35

The Devin-Adair Co.

Reviewed by Theodore C. Combs, '27

Wallace Johnson is president and founder of Up-Right, Inc., a successful scaffolding business. $\mathrm{He}$ also is mayor of Berkeley, California. In this book he philosophizes and reminisces about the role of the uncommon man in business, of whom he is, indeed, one.

To Johnson's man, freedom is for adventure, not for security. He succeeds by being enterprising, inventive, honest, responsible, and deeply appreciative of the values of his fellow man.

Johnson believes the businessman cannot ignore responsibility for his product and for the social consequences of his economic activity. Uncommon individuals can bring about a dramatic marriage of the technical inventiveness of modern man and the artistic creativity of the individual.

"There is one luxury America cannot afford: the uncommon man who is an uncommitted citizen. No longer can men of ability and influence keep themselves aloof from politics, telling themselves that voting alone is sufficient exercise of citizenship."

One might wish that uncommon men, Wallace Johnson stye, were commoner-and that more men might use his do-it-yourself kit, The Uncommon Man in American Business.

Thermodynamics of Multicomponent Systems

by Bruce H. Sage

Reinhold

A text for advanced study of the thermodynamics of multicomponent systems. The development, based on the work of J. W. Gibbs, is thorough and rigorous. Starting from the basic scientific concepts, the subject is treated in sufficient depth so as to show the engineering applications. Many illustrative examples are discussed, and a wealth of valuable numerical information is given. Dr. Sage is professor of chemical engineering at Caltech and has been associated with the Institute since 1934 . He is the holder of many honors and awards, including the Medal of Merit, U.S. Department of Defense.

Engineering and Science 